\title{
Efficient Photoelectrochemical Water Oxidation by Metal-Doped Bismuth Vanadate Photoanode with Iron Oxyhydroxide Electrocatalyst
}

\author{
Eun Jin Joo, Gisang Park, Ji Seon Gwak, Jong Hyeok Seo, Kyu Yeon Jang, \\ Kyung Hee Oh, and Ki Min Nam
}

Department of Chemistry, Mokpo National University, Jeonnam 534-729, Republic of Korea

Correspondence should be addressed to Ki Min Nam; namkimin.chem@gmail.com

Received 18 February 2016; Accepted 27 April 2016

Academic Editor: Vincenzo Baglio

Copyright (C) 2016 Eun Jin Joo et al. This is an open access article distributed under the Creative Commons Attribution License, which permits unrestricted use, distribution, and reproduction in any medium, provided the original work is properly cited.

Intensive attention has been currently focused on the discovery of semiconductor and proficient cocatalysts for eventual applications to the photoelectrochemical water splitting system. A W-Mo-doped $\mathrm{BiVO}_{4}$ semiconductor was prepared by the surfactantassisted thermal decomposition method on a fluorine-doped tin oxide conductive film. The W-Mo-doped $\mathrm{BiVO}_{4}$ films showed a porous morphology with the grain sizes of about $270 \mathrm{~nm}$. Because the hole diffusion length of $\mathrm{BiVO}_{4}$ is about $100 \mathrm{~nm}$, the $\mathrm{W}$-Mo-doped $\mathrm{BiVO}_{4}$ film in this study is an ideal candidate for the photoelectrochemical water oxidation. Iron oxyhydroxide $(\mathrm{FeOOH})$ electrocatalyst was chemically deposited on the $\mathrm{W}$-Mo-doped $\mathrm{BiVO}_{4}$ to investigate the effect of the electrocatalyst on the semiconductor. The W-Mo-doped $\mathrm{BiVO}_{4} / \mathrm{FeOOH}$ composite electrode showed enhanced activity compared to the pristine W-Modoped $\mathrm{BiVO}_{4}$ electrode for water oxidation reaction. The chemical deposition is a promising method for the deposition of FeOOH on semiconductor.

\section{Introduction}

Photoelectrochemical (PEC) water splitting using semiconductor electrode is a promising method of converting solar energy to chemical fuel $[1,2]$. Among the various semiconductor materials, metal oxides such as $\mathrm{TiO}_{2}, \mathrm{WO}_{3}, \mathrm{Fe}_{2} \mathrm{O}_{3}$, and $\mathrm{BiVO}_{4}$ have gained significant interest owing to their photochemical stability and low cost. However, they have a low PEC efficiency compared to the theoretical values, because of significant electron-hole recombination and slow surface kinetics [3, 4]. While a multitude of methods such as doping, morphology control, making composite structure, and adding electrocatalysts have been investigated for the improvement in PEC water splitting [5-8], achievement of theoretical conversion efficiency is still far from being reached.

$\mathrm{BiVO}_{4}$ has been intensively studied as a photoanode ( $\mathrm{n}$ type semiconductor) for PEC water oxidation, because it absorbs a large portion of the visible light and has a favorable valence band edge [9-11]. However, the slow carrier mobility in the bulk as well as fast recombination at the surface contributes to the poor water oxidation efficiency of $\mathrm{BiVO}_{4}$. The introduction of dopant such as $\mathrm{W}$ and $\mathrm{Mo}$ into $\mathrm{BiVO}_{4}$ has been found to enhance the PEC performance $[12,13]$. The dopant in $\mathrm{BiVO}_{4}$ can increase n-type conductivity and could significantly enhance the PEC activity. Furthermore, $\mathrm{W}$ and Mo codoping (W-Mo-doped $\mathrm{BiVO}_{4}$ ) has shown better performance than $\mathrm{W}$ or Mo alone for the $\mathrm{BiVO}_{4}$ [14]. Nanostructure can also enhance the kinetic parameters of the water oxidation reactions through the discrimination of bulk recombinations. For efficient PEC water oxidation, $\mathrm{BiVO}_{4}$ requires both particles smaller than its hole diffusion length $(\sim 100 \mathrm{~nm})[11]$ and the introduction of proper dopants. However, those are still not sufficient to overcome the low surface kinetic of $\mathrm{BiVO}_{4}$.

Recently, proficient electrocatalysts for eventual PEC applications have been intensively studied, but there is no guarantee that the best electrocatalysts will perform equally 
when integrated into a PEC water splitting system $[15,16]$. The source of catalytic improvement of electrocatalyst on semiconductor is not yet fully understood $[17,18]$. The nature of the loaded catalysts and their interaction with the semiconductor are important to further study the PEC water splitting. Recently, a number of studies have focused on the potential applications of iron oxyhydroxide $(\mathrm{FeOOH})$ as the cocatalysts [15]. Unfortunately, most of the researches considered to date have only focused on the photodeposition or electrodeposition method $[7,15]$.

In this study, we report a facile formation of W-Mo-doped $\mathrm{BiVO}_{4}$ films on fluorine-doped tin oxide (FTO) for the PEC water oxidation. The W-Mo-doped $\mathrm{BiVO}_{4}$ films showed a porous morphology with the grain sizes of about $270 \mathrm{~nm}$. Because the hole diffusion length of $\mathrm{BiVO}_{4}$ is about $100 \mathrm{~nm}$, the $\mathrm{W}$-Mo-doped $\mathrm{BiVO}_{4}$ film in this study is an ideal candidate for effective charge separation. Furthermore, $\mathrm{FeOOH}$ cocatalyst was chemically deposited on the W-Mo-doped $\mathrm{BiVO}_{4}$ films by the oxidation of $\mathrm{FeSO}_{4}$ to investigate the effect of electrocatalysts on the semiconductor surface. The W-Mo-doped $\mathrm{BiVO}_{4} / \mathrm{FeOOH}$ composites showed enhanced PEC water oxidation performance.

\section{Experimental Procedures}

2.1. Materials. Fluorine-doped tin oxide (FTO, TEC 15, WY-GMS) coated glass was used as the substrate for the thin film electrodes. $\left(\mathrm{NH}_{4}\right)_{6} \mathrm{H}_{2} \mathrm{~W}_{12} \mathrm{O}_{40} \cdot x \mathrm{H}_{2} \mathrm{O}(\geq 99.0 \%$, Sigma-Aldrich), $\mathrm{Bi}\left(\mathrm{NO}_{3}\right)_{3} \cdot 5 \mathrm{H}_{2} \mathrm{O}$ (99.999\%, Sigma-Aldrich), $\left(\mathrm{NH}_{4}\right)_{6} \mathrm{Mo}_{7} \mathrm{O}_{24} \cdot 4 \mathrm{H}_{2} \mathrm{O}$ (99.98\%, Sigma-Aldrich), and $\mathrm{VCl}_{3}$ (99\%, Alfa-Aesar) were used as the metal precursor salts and used as received. In addition, Nafion (5\%, Sigma-Aldrich) and $\mathrm{NaOCl}(10 \%), \mathrm{Na}_{2} \mathrm{SO}_{4}, \mathrm{Na}_{2} \mathrm{SO}_{3}, \mathrm{Na}_{2} \mathrm{HPO}_{4}, \mathrm{NaH}_{2} \mathrm{PO}_{4}$, ethylene glycol (99.0\%), acetone (99.0\%), and ethanol (99.5\%) were purchased from Daejung Chemicals (Korea). Deionized (DI) water was used as the solvent in electrochemical experiments.

2.2. Preparation of W-Mo-Doped $\mathrm{BiVO}_{4}$ and Undoped $\mathrm{BiVO}_{4}$ Electrodes. FTO substrates were first cleaned in deionized water and ethanol and then sonicated in ethanol for at least 1h. A drop-casting technique was used to create the thin film electrodes. Here, $10 \mathrm{mM} \mathrm{W}$-Mo-doped $\mathrm{BiVO}_{4}$ precursor (the atomic ratio in between $\mathrm{Bi}, \mathrm{V}, \mathrm{W}$, and Mo was $4.6: 4.6: 0.2: 0.6)$ in ethylene glycol solution was prepared. Nafion solution was added to the precursor solution (volume ratio between precursor and Nafion solution was 1:5) and then applied onto an FTO substrate. The prepared films were annealed at $500^{\circ} \mathrm{C}$ for $3 \mathrm{~h}$ (with a $3 \mathrm{~h}$ ramp time) in air to form the W-Mo-doped $\mathrm{BiVO}_{4}$ thin film. The existence of Nafion in precursor solution tends to give reproducible growth on FTO substrate. For undoped $\mathrm{BiVO}_{4}$ precursor, the atomic ratio in between $\mathrm{Bi}$ and $\mathrm{V}$ was 1:1 in ethylene glycol.

2.3. Chemical Deposition of FeOOH on W-Mo-Doped $\mathrm{BiVO}_{4}$ Film. Chemical deposition of $\mathrm{FeOOH}$ was carried out by adding $30 \mathrm{~mL}$ of $1.5 \mathrm{M} \mathrm{NaOCl}$ to $15 \mathrm{~mL}$ of $1.0 \mathrm{M} \mathrm{FeSO}_{4}$ solution. The solution was kept at $30^{\circ} \mathrm{C}$ for $3 \mathrm{~h}$ in air in the presence of W-Mo-doped $\mathrm{BiVO}_{4}$ film, and the resulting W-Mo-doped $\mathrm{BiVO}_{4} / \mathrm{FeOOH}$ electrode was washed with ethanol and DI water. $\mathrm{FeOOH}$ was also deposited on undoped $\mathrm{BiVO}_{4}$ with the same method.

2.4. Photodeposition of $\mathrm{FeOOH}$ on $\mathrm{W}$-Mo-Doped $\mathrm{BiVO}_{4}$ Film. Photodeposition of $\mathrm{FeOOH}$ on the W-Mo-doped $\mathrm{BiVO}_{4}$ was carried out in a $0.1 \mathrm{M} \mathrm{FeSO}_{4}$ solution using a threeelectrode cell setup. For the photodeposition, an external bias of $0.3 \mathrm{~V}$ versus $\mathrm{Ag} / \mathrm{AgCl}$ was applied. The light was illuminated through the FTO side (backside) with the light intensity of $100 \mathrm{~mW} / \mathrm{cm}^{2}$. Photodeposition was performed for $30 \mathrm{~min}$, and the electrode was washed with ethanol and DI water.

2.5. Electrochemical Characterization of Electrodes. Electrochemical characterization was performed in a specially designed cell in a three-electrode configuration with the thin film as the working electrode, a Pt wire counter electrode, and an $\mathrm{Ag} / \mathrm{AgCl}$ reference electrode. The working electrode with the actual geometric area of $0.28 \mathrm{~cm}^{2}$ was exposed to electrolyte solution. A $150 \mathrm{~W}$ xenon lamp (ABET Technologies) was used as the light source in the PEC characterization step, and light illumination area was $0.28 \mathrm{~cm}^{2}$. Chopped light linear sweep voltammetry (LSV) was utilized to obtain the photocurrent responses using a DY2321 potentiostat (DigiIvy). The light chopping frequency was set at $2 \mathrm{~Hz}$ and the PEC measurements were performed by backside illumination in aqueous solutions of $0.1 \mathrm{M} \mathrm{Na}_{2} \mathrm{SO}_{4}$ with a phosphate buffer $(\mathrm{pH} 7)$ for water oxidation. In all tests, the intensity of the lamp on the sample was measured to be $100 \mathrm{~mW} / \mathrm{cm}^{2}$ using a Si solar cell (AIST). A $425 \mathrm{~nm}$ long-pass filter was used to cut the UV portion of the spectrum and to provide only visible light illumination. A monochromator (ORIEL) was used to obtain the action spectra of photoresponse as a function of wavelength. Because the preparation of W-Modoped $\mathrm{BiVO}_{4}$ electrode is reproducible, it always shows the same photocurrents of each sample.

2.6. Materials Characterization of Electrodes. UV-Vis absorption spectra were acquired with a Lambda 3B Spectrophotometer (Perkin-Elmer) for wavelengths from 300 to $900 \mathrm{~nm}$. The thin film electrodes were characterized by scanning electron microscopy (SEM, Philips XL30SFEG operated at 10 and $30 \mathrm{kV}$ ). The X-ray diffraction data was measured using $\mathrm{Cu} K_{\alpha}$ radiations at $40 \mathrm{kV}$ and $100 \mathrm{~mA}$ (Rigaku, Dmax$\mathrm{RB}$ diffractometer). X-ray photoelectron spectroscopy (XPS) measurements were taken using a $K_{\alpha}$ spectrometer with an $\mathrm{X}$-ray source of $\mathrm{Al} K_{\alpha}$ and at a pass energy level of $40 \mathrm{eV}$.

\section{Results and Discussion}

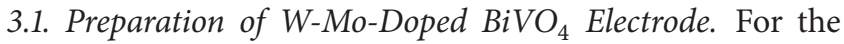
facile preparation of $\mathrm{W}$-Mo-doped $\mathrm{BiVO}_{4}$ structure, thin film electrodes were prepared by surfactant-assisted thermal decomposition method on an FTO substrate. Figure 1(a) shows the scanning electron microscopy (SEM) of the WMo-doped $\mathrm{BiVO}_{4}$ thin film electrode, indicating a porous 


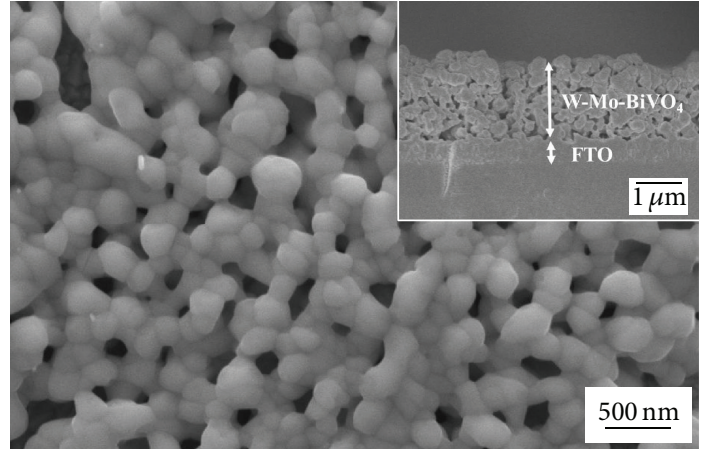

(a)

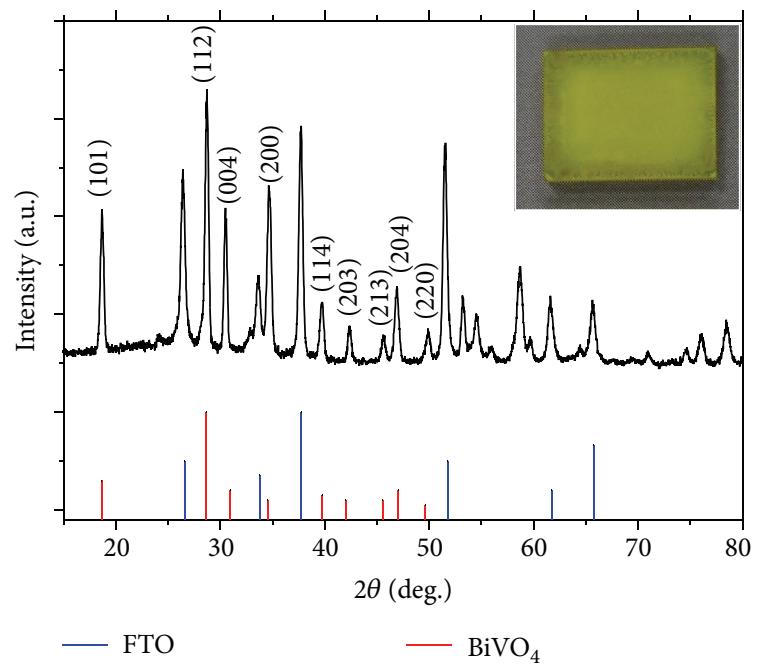

(b)

FIgURE 1: (a) SEM top-view and cross section image (inset) of the $\mathrm{W}$-Mo-doped $\mathrm{BiVO}_{4}$, (b) XRD patterns of the W-Mo-doped $\mathrm{BiVO}_{4}$ (red line) and FTO substrate (blue line), and photographic image (inset) of the W-Mo-doped $\mathrm{BiVO}_{4}$.

network with the grain sizes of $274.8 \pm 63.7 \mathrm{~nm}$. The cross section SEM image of the $\mathrm{W}$-Mo-doped $\mathrm{BiVO}_{4}$ shows the film with a thickness of about $1.1 \mu \mathrm{m}$ (inset). The porous structures can allow the electrolyte to easily diffuse within the $\mathrm{BiVO}_{4}$, increasing the contact area and shortening the hole diffusion distance [13]. Because the hole diffusion length of $\mathrm{BiVO}_{4}$ is about $100 \mathrm{~nm}$ [11], the W-Mo-doped $\mathrm{BiVO}_{4}$ thin film in this study is ideal for effective charge separation. Notably, the precursor solution without Nafion increased the grain sizes of the $\mathrm{W}$-Mo-doped $\mathrm{BiVO}_{4}$ and irregularly formed on the FTO substrate $(351.5 \pm 82.8 \mathrm{~nm}$, see Figure S1 in Supplementary Material available online at http://dx.doi.org/10.1155/2016/1827151). The existence of Nafion in the precursor solution tends to provide small grain sizes as well as uniform growth on the FTO substrate (Figure 1(b) inset). The X-ray diffraction (XRD) peaks corresponded to the monoclinic structure of $\mathrm{BiVO}_{4}$ (Figure $1(\mathrm{~b})$ ). Any secondary phase in the XRD patterns was not observed. However, a shift and merging of the XRD peaks at 34, 47, and $59^{\circ}$ were observed, indicating that $\mathrm{W}$ and Mo were well dissolved in the $\mathrm{BiVO}_{4}$ solid solution [14].
3.2. PEC at the $W$-Mo-Doped $\mathrm{BiVO}_{4}$ Electrode. The PEC performance of the $\mathrm{W}$-Mo-doped $\mathrm{BiVO}_{4}$ thin film electrode was studied by linear sweep voltammetry (LSV) for both sulfite oxidation $\left(0.1 \mathrm{M} \mathrm{Na}_{2} \mathrm{SO}_{3}+0.1 \mathrm{M} \mathrm{Na}_{2} \mathrm{SO}_{4}\right)$ and water oxidation ( $0.1 \mathrm{M} \mathrm{Na}_{2} \mathrm{SO}_{4}+0.1 \mathrm{M}$ phosphate buffered, $\mathrm{pH}$ $7)$. The LSV was conducted from -0.6 to $+0.8 \mathrm{~V}$ versus $\mathrm{Ag} / \mathrm{AgCl}$ at a scan rate of $20 \mathrm{mV} / \mathrm{s}$ with chopped light under UV-visible and visible (>425 nm) irradiations (Figure 2). The $\mathrm{W}$-Mo-doped $\mathrm{BiVO}_{4}$ electrode successfully generated anodic photocurrents (n-type character). Because the sulfite oxidation has extremely fast oxidation kinetics, the surface recombination is negligible $[14,15]$. The sulfite oxidation is thermodynamically and kinetically favorable, and thus it has a more negative onset potential compared to that of water oxidation (Figure 2). An early onset potential $(-0.5 \mathrm{~V}$ versus $\mathrm{Ag} / \mathrm{AgCl})$ and a rapid increase in photocurrent of $1.6 \mathrm{~mA} / \mathrm{cm}^{2}(0.6 \mathrm{~V}$ versus $\mathrm{Ag} / \mathrm{AgCl})$ for sulfite oxidation on the $\mathrm{W}$-Mo-doped $\mathrm{BiVO}_{4}$ electrode indicated an excellent fill factor. However, nanosized structures are also associated with significant disadvantages, such as an increased number of grain boundaries and a reduced spacecharge region [19], resulting in much lower efficiency of the $\mathrm{W}$-Mo-doped $\mathrm{BiVO}_{4}$ electrode than the theoretical value $\left(7.5 \mathrm{~mA} / \mathrm{cm}^{2}\right)$ [20]. Furthermore, the photocurrent from the $\mathrm{W}$-Mo-doped $\mathrm{BiVO}_{4}$ electrode for water oxidation is far lower than that of sulfite oxidation. The significant reduction in photocurrent demonstrates that the water oxidation on the $\mathrm{W}$-Mo-doped $\mathrm{BiVO}_{4}$ electrode is mainly limited by poor water oxidation kinetics on the electrode surface. This result indicates that a considerably improved photocurrent can be possible when the W-Mo-doped $\mathrm{BiVO}_{4}$ electrode is coupled with a proper water oxidation cocatalyst.

3.3. Chemical Deposition of FeOOH on the W-Mo-Doped $\mathrm{BiVO}_{4}$ Electrode. Efficient PEC water splitting requires both highly active semiconductor photoelectrode and proficient electrocatalyst, that is, cocatalyst. Catalyst-modified $\mathrm{BiVO}_{4}$ enhanced PEC efficiency and also noticeably improved the stability [7, 21]. Recently, a number of studies have focused on the potential applications of $\mathrm{FeOOH}$ as the cocatalyst [15]. Unfortunately, most of the researches considered to date have only used the photodeposition or electrodeposition method on the semiconductor $[7,15]$.

To improve water oxidation kinetics, a thin layer of $\mathrm{FeOOH}$ catalyst was chemically deposited. The chemical deposition of $\mathrm{FeOOH}$ on the $\mathrm{W}$-Mo-doped $\mathrm{BiVO}_{4}$ electrode was carried out in a $1.0 \mathrm{M} \mathrm{FeSO}_{4}$ with $1.5 \mathrm{M} \mathrm{NaOCl}$ solution. $\mathrm{FeSO}_{4}$ was oxidized to $\mathrm{FeOOH}$ by the $\mathrm{NaOCl}$ reduction reaction [22] and then deposited on the $\mathrm{W}$-Mo-doped $\mathrm{BiVO}_{4}$ electrode. $\mathrm{Fe}^{3+}$ ions are insoluble in an aqueous medium [23] and thus precipitated as FeOOH on the W-Mo-doped $\mathrm{BiVO}_{4}$ electrode. As-deposited $\mathrm{FeOOH}$ film was amorphous. To determine the chemical state of the film, X-ray photoelectron spectroscopy (XPS) was performed (Figure 3 ). In the Fe $2 \mathrm{p}_{1 / 2}$ and $\mathrm{Fe} 2 \mathrm{p}_{3 / 2}$ region, the spectra have three major peaks assigned at 724, 718, and $712.5 \mathrm{eV}$ for $\mathrm{Fe}^{3+}[24,25]$. In the $\mathrm{O}$ 1 s region, the lowest binding energy peak at $529.7 \mathrm{eV}$ can be 


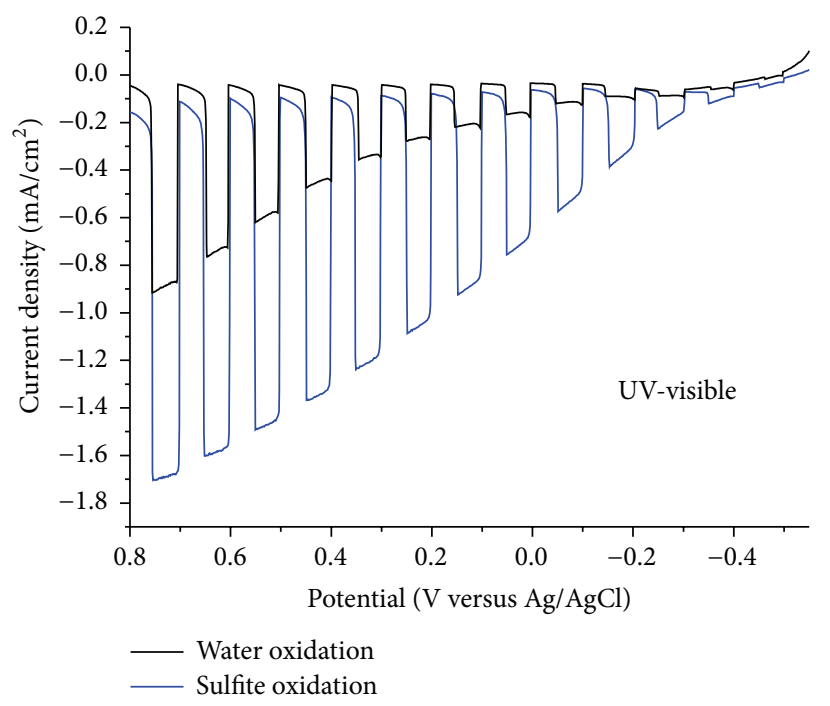

(a)

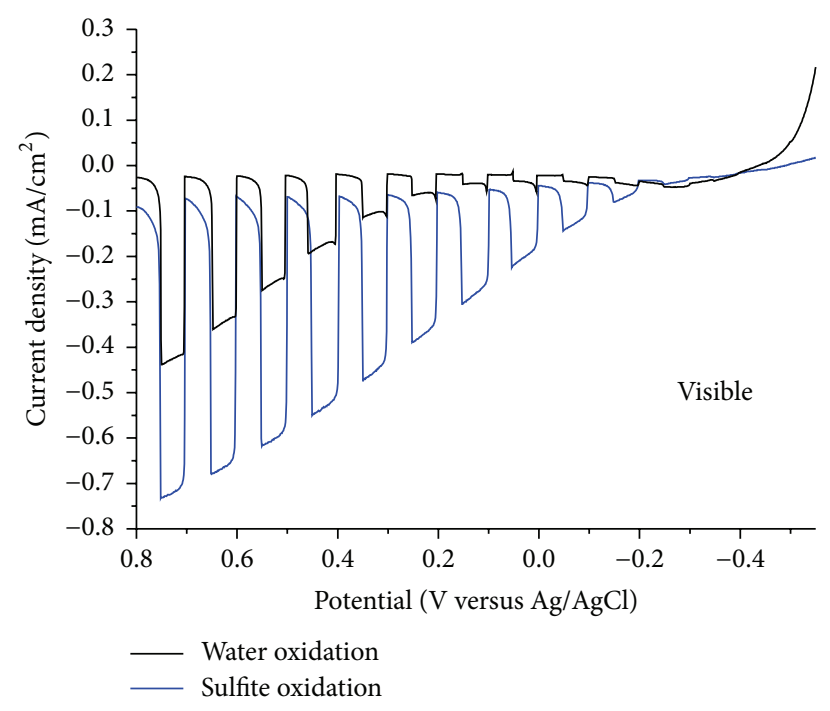

(b)

FIGURE 2: LSVs for the sulfite oxidation $\left(0.1 \mathrm{M} \mathrm{Na}_{2} \mathrm{SO}_{3}+0.1 \mathrm{M} \mathrm{Na}_{2} \mathrm{SO}_{4}\right)$ and water oxidation $\left(0.1 \mathrm{M} \mathrm{Na}_{2} \mathrm{SO}_{4}+0.1 \mathrm{M}\right.$ phosphate buffered, pH 7) using the W-Mo-doped $\mathrm{BiVO}_{4}$ under (a) UV-visible and (b) visible light irradiation. Scan rate: $20 \mathrm{mV} / \mathrm{s}$. Light intensity: $100 \mathrm{~mW} / \mathrm{cm}^{2}$.

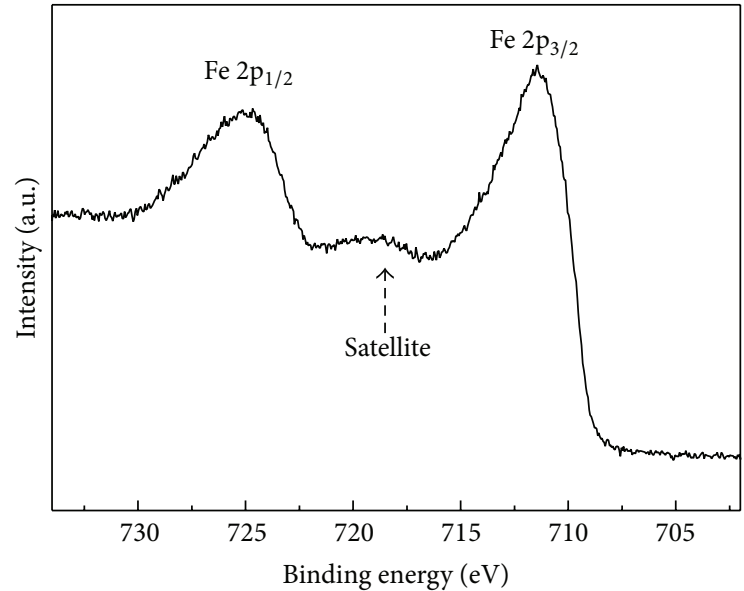

(a)

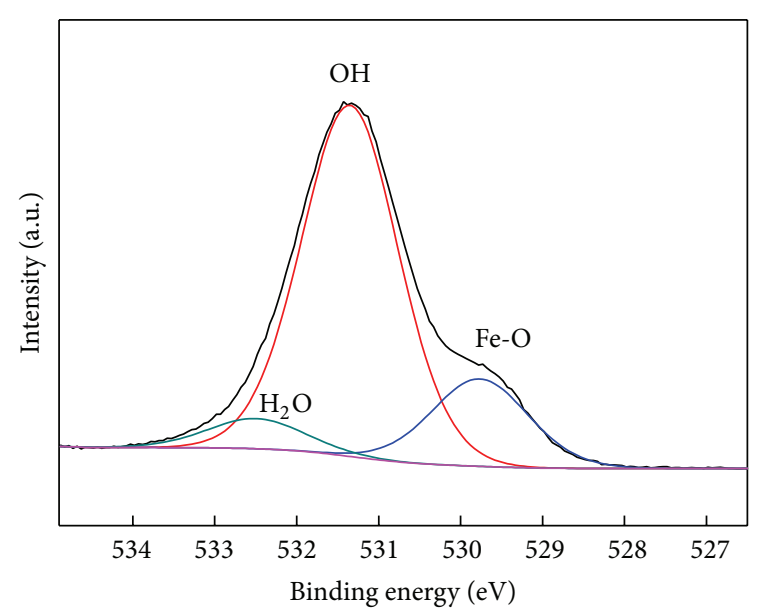

(b)

FIgURE 3: XPS spectra of the FeOOH on the W-Mo-doped $\mathrm{BiVO}_{4}$ in the (a) Fe 2p and (b) O 1s regions.

assigned to oxygen atoms in the iron oxide lattice, $\mathrm{O}$ 1s (Fe$\mathrm{O})$, and the peak at $532.1 \mathrm{eV}$ is assigned to lattice hydroxyl group, $\mathrm{O}$ 1s ( Fe-OH), that matched well with $\mathrm{FeOOH}$ spectra [24]. Figure 4 shows the SEM image of $\mathrm{FeOOH}$ on the WMo-doped $\mathrm{BiVO}_{4}$ (W-Mo-doped $\mathrm{BiVO}_{4} / \mathrm{FeOOH}$ ), indicating that $\mathrm{FeOOH}$ was uniformly covered on the electrode surface, while maintaining the shape of the W-Mo-doped $\mathrm{BiVO}_{4}$. This method is simple and cost effective compared to electrodeposition or photodeposition.

3.4. $\mathrm{PEC}$ at the $\mathrm{W}$-Mo-Doped $\mathrm{BiVO}_{4} / \mathrm{FeOOH}$ Electrode. The photocurrents for water oxidation from the resulting W-Modoped $\mathrm{BiVO}_{4} / \mathrm{FeOOH}$ electrode were significantly higher than that of the $\mathrm{W}$-Mo-doped $\mathrm{BiVO}_{4}$ electrode (Figure 5). The
W-Mo-doped $\mathrm{BiVO}_{4} / \mathrm{FeOOH}$ composite electrode attained almost 2-fold higher photocurrent than the W-Mo-doped $\mathrm{BiVO}_{4}$ for water oxidation reaction at $+0.6 \mathrm{~V}$ versus $\mathrm{Ag} / \mathrm{AgCl}$. The onset potential of $\mathrm{W}$-Mo-doped $\mathrm{BiVO}_{4} / \mathrm{FeOOH}$ electrode is slightly shifted to the negative direction indicating reduced surface recombination processes at the small overpotential value. The action spectra of the W-Mo-doped $\mathrm{BiVO}_{4} / \mathrm{FeOOH}$ electrode show typical photocurrents at $+0.3 \mathrm{~V}$ versus $\mathrm{Ag} / \mathrm{AgCl}$ depending on the wavelength with a $10 \mathrm{~nm}$ interval (Figure 6). The bandgaps were determined from the wavelengths for the onset of photocurrent. The $\mathrm{W}$-Mo-doped $\mathrm{BiVO}_{4} / \mathrm{FeOOH}$ showed the same onset wavelength as that of the $\mathrm{W}$-Mo-doped $\mathrm{BiVO}_{4}(540 \mathrm{~nm})$, indicating that the bandgap of $\mathrm{W}$-Mo-doped $\mathrm{BiVO}_{4} / \mathrm{FeOOH}$ did not 


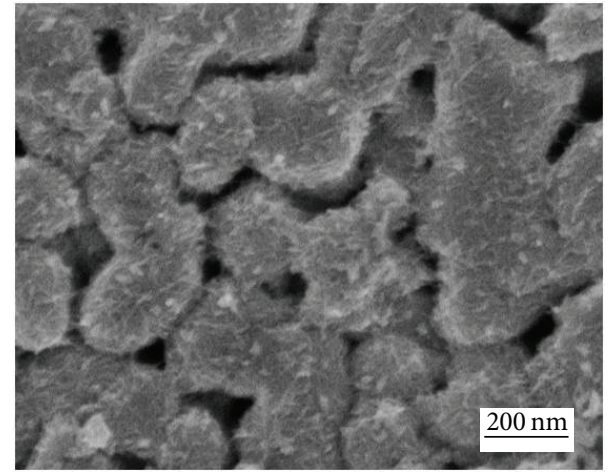

Figure 4: SEM image of FeOOH on the W-Mo-doped $\mathrm{BiVO}_{4}$.

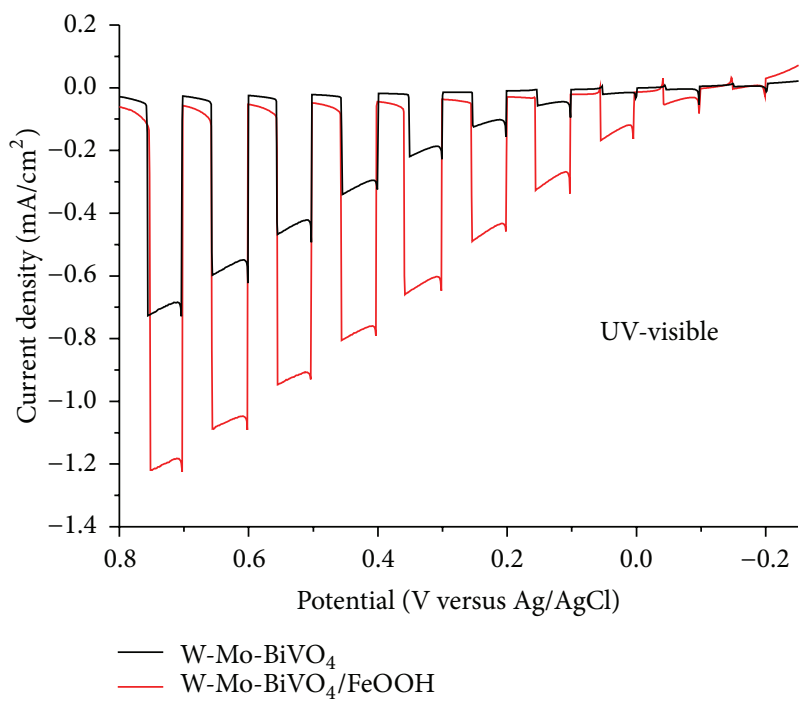

FIgURE 5: LSVs of the W-Mo-doped $\mathrm{BiVO}_{4}$ and W-Mo-doped $\mathrm{BiVO}_{4} / \mathrm{FeOOH}$ electrodes under UV-visible illumination in phosphate buffer $(\mathrm{pH} \mathrm{7})$. Scan rate: $20 \mathrm{mV} / \mathrm{s}$. Light intensity: $100 \mathrm{~mW} / \mathrm{cm}^{2}$.

change (Figure S2(a)). The bandgap can also be estimated from the onset of the UV-visible absorbance spectrum (Figure S2(b)). From the absorbance data, the W-Mo-doped $\mathrm{BiVO}_{4}$ sample showed direct transitions with the bandgaps of $\sim 2.4 \mathrm{eV}$. The bandgap obtained from the absorbance agrees well with the action spectrum data, and the onset wavelength of the W-Mo-doped $\mathrm{BiVO}_{4}$ is essentially the same.

To assess the stability of both the W-Mo-doped $\mathrm{BiVO}_{4}$ and W-Mo-doped $\mathrm{BiVO}_{4} / \mathrm{FeOOH}$ electrodes over time, chronoamperometry was carried out at $+0.3 \mathrm{~V}$ versus $\mathrm{Ag} / \mathrm{AgCl}$ under UV-visible irradiation (Figure 7). After an initial drop, the photocurrent of the W-Mo-doped $\mathrm{BiVO}_{4} / \mathrm{FeOOH}$ was stabilized at a steady-state value of $0.3 \mathrm{~mA} / \mathrm{cm}^{2}$ at $0.3 \mathrm{~V}$ versus $\mathrm{Ag} / \mathrm{AgCl}$. The presence of $\mathrm{FeOOH}$ electrocatalyst effectively suppresses the photochemical deactivation of the W-Mo-doped $\mathrm{BiVO}_{4}$. This result demonstrates the promise of chemically deposited $\mathrm{FeOOH}$ electrocatalyst for improving the photocurrent as well as the stability of the W-Mo-doped $\mathrm{BiVO}_{4}$. Furthermore, when FeOOH catalyst

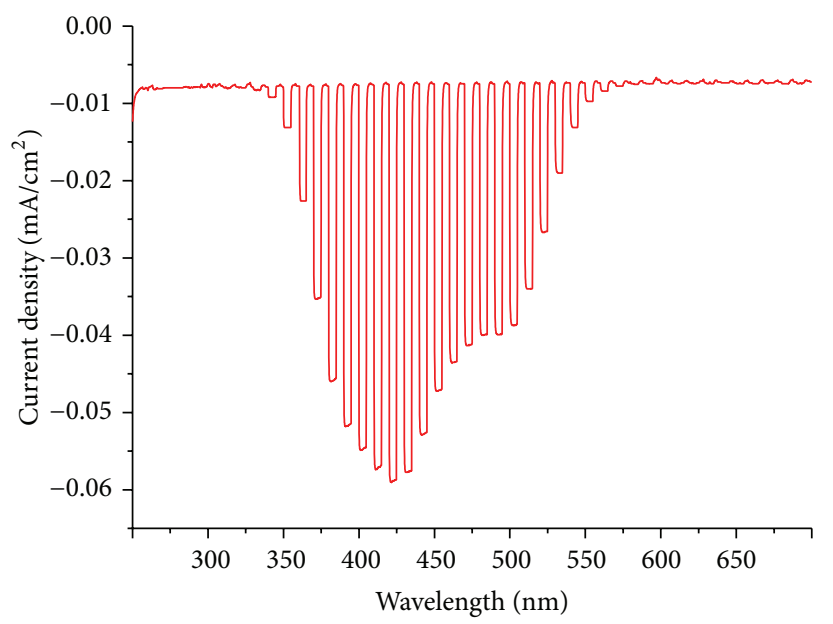

Figure 6: Action spectrum of the W-Mo-doped $\mathrm{BiVO}_{4} / \mathrm{FeOOH}$ electrode at an applied potential of $0.3 \mathrm{~V}$ versus $\mathrm{Ag} / \mathrm{AgCl}$ under $\mathrm{UV}$ visible illumination in phosphate buffer ( $\mathrm{pH} 7)$.

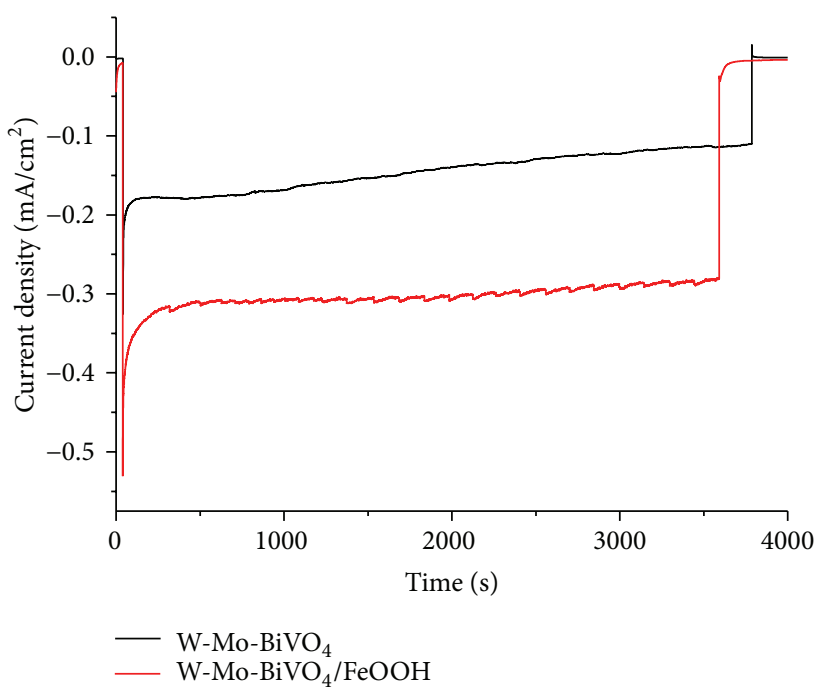

FIgURE 7: Current-time response curves of the W-Mo-doped $\mathrm{BiVO}_{4}$, and $\mathrm{W}-\mathrm{Mo}$-doped $\mathrm{BiVO}_{4} / \mathrm{FeOOH}$ electrodes at an applied potential of $0.3 \mathrm{~V}$ versus $\mathrm{Ag} / \mathrm{AgCl}$ in phosphate buffer ( $\mathrm{pH} 7$ ).

was deposited on undoped $\mathrm{BiVO}_{4}$, the photocurrent also showed significantly enhanced PEC efficiency (Figure 8).

For comparison, a $\mathrm{FeOOH}$ layer was photodeposited on the W-Mo-doped $\mathrm{BiVO}_{4}$ electrode. The photocurrents for water oxidation from the resulting W-Mo-doped $\mathrm{BiVO}_{4} / \mathrm{FeOOH}$ electrode also showed enhanced activity compared to that of the $\mathrm{W}$-Mo-doped $\mathrm{BiVO}_{4}$ electrode (Figure S3). The photocurrent of chemically deposited $\mathrm{FeOOH}$ on the $\mathrm{W}$-Mo-doped $\mathrm{BiVO}_{4}$ showed a slightly higher value than that of photodeposited $\mathrm{FeOOH}$ sample, indicating that the chemical deposition can be an alternative method for the preparation of semiconductor-FeOOH composite for PEC water oxidation. This result indicates that the chemically deposited $\mathrm{FeOOH}$ is promising for improving the PEC activity for water oxidation. 


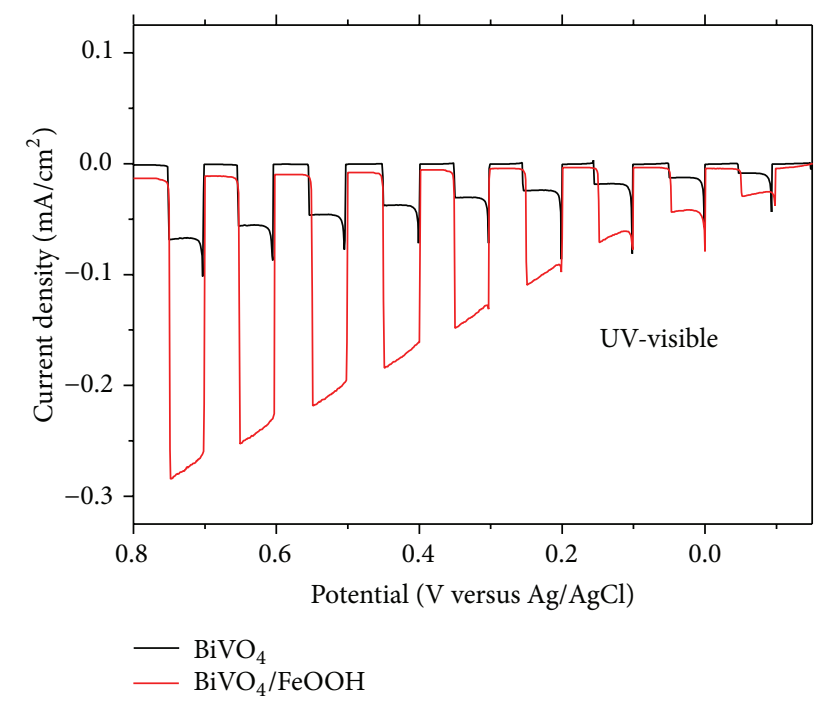

FIgURE 8: $\mathrm{LSV}_{\mathrm{s}}$ of $\mathrm{BiVO}_{4}$ and $\mathrm{BiVO}_{4} / \mathrm{FeOOH}$ electrodes under UVvisible illumination in phosphate buffer ( $\mathrm{pH} 7)$. Scan rate: $20 \mathrm{mV} / \mathrm{s}$. Light intensity: $100 \mathrm{~mW} / \mathrm{cm}^{2}$.

\section{Conclusions}

A W-Mo-doped $\mathrm{BiVO}_{4}$ semiconductor was prepared by Nafion-assisted thermal decomposition method on an FTO substrate. The W-Mo-doped $\mathrm{BiVO}_{4}$ electrodes showed a porous network with the grain sizes of $\sim 270 \mathrm{~nm}$. Because the hole diffusion length of $\mathrm{BiVO}_{4}$ is about $100 \mathrm{~nm}$, the $\mathrm{BiVO}_{4}$ film in this study was found to be ideal for effective charge separation. $\mathrm{FeOOH}$ electrocatalyst was chemically deposited by the oxidation of $\mathrm{FeSO}_{4}$ on the W-Mo-doped $\mathrm{BiVO}_{4}$. The $\mathrm{W}$-Mo-doped $\mathrm{BiVO}_{4} / \mathrm{FeOOH}$ composite electrode attained at least 2-fold higher photocurrent at $0.3 \mathrm{~V}$ (versus $\mathrm{Ag} / \mathrm{AgCl}$ ) than that of the $\mathrm{W}$-Mo-doped $\mathrm{BiVO}_{4}$ for water oxidation reaction. Furthermore, the W-Mo-doped $\mathrm{BiVO}_{4} / \mathrm{FeOOH}$ composite showed high photochemical stability. This result demonstrates that the chemically deposited $\mathrm{FeOOH}$ is promising for improving the activity as well as the stability of the water oxidation reaction.

\section{Competing Interests}

The authors declare that there is no conflict of interests regarding the publication of this paper.

\section{Acknowledgments}

This work was supported by the Basic Science Research Program through the National Research Foundation of Korea (NRF) funded by the Ministry of Science, ICT \& Future Planning (NRF-2015R1C1A1A02037373).

\section{References}

[1] A. Fujishima and K. Honda, "Electrochemical photolysis of water at a semiconductor electrode," Nature, vol. 238, no. 5358, pp. 37-38, 1972.
[2] A. J. Bard and M. A. Fox, "Artificial photosynthesis: solar splitting of water to hydrogen and oxygen," Accounts of Chemical Research, vol. 28, no. 3, pp. 141-145, 1995.

[3] Y. Park, K. J. McDonald, and K.-S. Choi, "Progress in bismuth vanadate photoanodes for use in solar water oxidation," Chemical Society Reviews, vol. 42, no. 6, pp. 2321-2337, 2013.

[4] J. R. Swierk and T. E. Mallouk, "Design and development of photoanodes for water-splitting dye-sensitized photoelectrochemical cells," Chemical Society Reviews, vol. 42, no. 6, pp. 2357-2387, 2013.

[5] A. J. Nozik, "Photoelectrochemistry: applications to solar energy conversion," Annual Review of Physical Chemistry, vol. 29, pp. 189-222, 1978.

[6] S. K. Pilli, T. G. Deutsch, T. E. Furtak, L. D. Brown, J. A. Turner, and A. M. Herring, " $\mathrm{BiVO}_{4} / \mathrm{CuWO}_{4}$ heterojunction photoanodes for efficient solar driven water oxidation," Physical Chemistry Chemical Physics, vol. 15, no. 9, pp. 3273-3278, 2013.

[7] D. K. Zhong, S. Choi, and D. R. Gamelin, "Near-complete suppression of surface recombination in solar photoelectrolysis by 'Co-Pi' catalyst-modified $\mathrm{W}: \mathrm{BiVO}_{4}$," Journal of the American Chemical Society, vol. 133, no. 45, pp. 18370-18377, 2011.

[8] A. Kudo and Y. Miseki, "Heterogeneous photocatalyst materials for water splitting," Chemical Society Reviews, vol. 38, no. 1, pp. 253-278, 2009.

[9] A. Kudo, K. Omori, and H. Kato, "A novel aqueous process for preparation of crystal form-controlled and highly crystalline $\mathrm{BiVO}_{4}$ powder from layered vanadates at room temperature and its photocatalytic and photophysical properties," Journal of the American Chemical Society, vol. 121, no. 49, pp. 11459-11467, 1999.

[10] J. Su, L. Guo, N. Bao, and C. A. Grimes, "Nanostructured $\mathrm{WO}_{3} / \mathrm{BiVO}_{4}$ heterojunction films for efficient photoelectrochemical water splitting," Nano Letters, vol. 11, no. 5, pp. 19281933, 2011.

[11] A. J. E. Rettie, H. C. Lee, L. G. Marshall et al., "Combined charge carrier transport and photoelectrochemical characterization of BiVO4 single crystals: Intrinsic behavior of a complex metal oxide," Journal of the American Chemical Society, vol. 135, no. 30, pp. 11389-11396, 2013.

[12] F. F. Abdi, L. Han, A. H. M. Smets, M. Zeman, B. Dam, and R. V. D. Krol, "Efficient solar water splitting by enhanced charge separation in a bismuth vanadate-silicon tandem photoelectrode," Nature Communications, vol. 4, article 3195, 2013.

[13] W. Luo, Z. Yang, Z. Li et al., "Solar hydrogen generation from seawater with a modified $\mathrm{BiVO}_{4}$ photoanode," Energy and Environmental Science, vol. 4, no. 10, pp. 4046-4051, 2011.

[14] H. S. Park, K. E. Kweon, H. Ye, E. Paek, G. S. Hwang, and A. J. Bard, "Factors in the metal doping of $\mathrm{BiVO}_{4}$ for improved photoelectrocatalytic activity as studied by scanning electrochemical microscopy and first-principles density-functional calculation," Journal of Physical Chemistry C, vol. 115, no. 36, pp. 17870-17879, 2011.

[15] T. W. Kim and K.-S. Choi, "Nanoporous $\mathrm{BiVO}_{4}$ photoanodes with dual-layer oxygen evolution catalysts for solar water splitting," Science, vol. 343, no. 6174, pp. 990-994, 2014.

[16] D. R. Gamelin, "Water splitting: catalyst or spectator?” Nature Chemistry, vol. 4, no. 12, pp. 965-967, 2012.

[17] F. L. Formal, K. Sivula, and M. Grätzel, "The transient photocurrent and photovoltage behavior of a hematite photoanode under working conditions and the influence of surface treatments," The Journal of Physical Chemistry C, vol. 116, no. 51, pp. 2670726720, 2012. 
[18] K. Sivula, "Metal oxide photoelectrodes for solar fuel production, surface traps, and catalysis," Journal of Physical Chemistry Letters, vol. 4, no. 10, pp. 1624-1633, 2013.

[19] F. E. Osterloh, "Inorganic nanostructures for photoelectrochemical and photocatalytic water splitting," Chemical Society Reviews, vol. 42, no. 6, pp. 2294-2320, 2013.

[20] C. Liu, N. P. Dasgupta, and P. Yang, "Semiconductor nanowires for artificial photosynthesis," Chemistry of Materials, vol. 26, no. 1, pp. 415-422, 2014.

[21] H. Ye, H. S. Park, and A. J. Bard, "Screening of electrocatalysts for photoelectrochemical water oxidation on $\mathrm{W}$-doped $\mathrm{BiVO}_{4}$ photocatalysts by scanning electrochemical microscopy," Journal of Physical Chemistry C, vol. 115, no. 25, pp. 12464-12470, 2011.

[22] G. Qui, Z. Gao, H. Yin, X. Feng, W. Tan, and F. Liu, "Synthesis of $\mathrm{MnPO}_{4} \cdot \mathrm{H}_{2} \mathrm{O}$ by refluxing process at atmospheric pressure," Solid State Sciences, vol. 12, no. 5, pp. 808-813, 2010.

[23] K. J. McDonald and K.-S. Choi, "A new electrochemical synthesis route for a $\mathrm{BiOI}$ electrode and its conversion to a highly efficient porous $\mathrm{BiVO}_{4}$ photoanode for solar water oxidation," Energy and Environmental Science, vol. 5, no. 9, pp. 8553-8557, 2012.

[24] J. Baltrusaitis, D. M. Cwiertny, and V. H. Grassian, "Adsorption of sulfur dioxide on hematite and goethite particle surfaces," Physical Chemistry Chemical Physics, vol. 9, no. 41, pp. 55425554, 2007.

[25] T. Yamashita and P. Hayes, "Analysis of XPS spectra of $\mathrm{Fe}^{2+}$ and $\mathrm{Fe}^{3+}$ ions in oxide materials," Applied Surface Science, vol. 254, no. 8, pp. 2441-2449, 2008. 

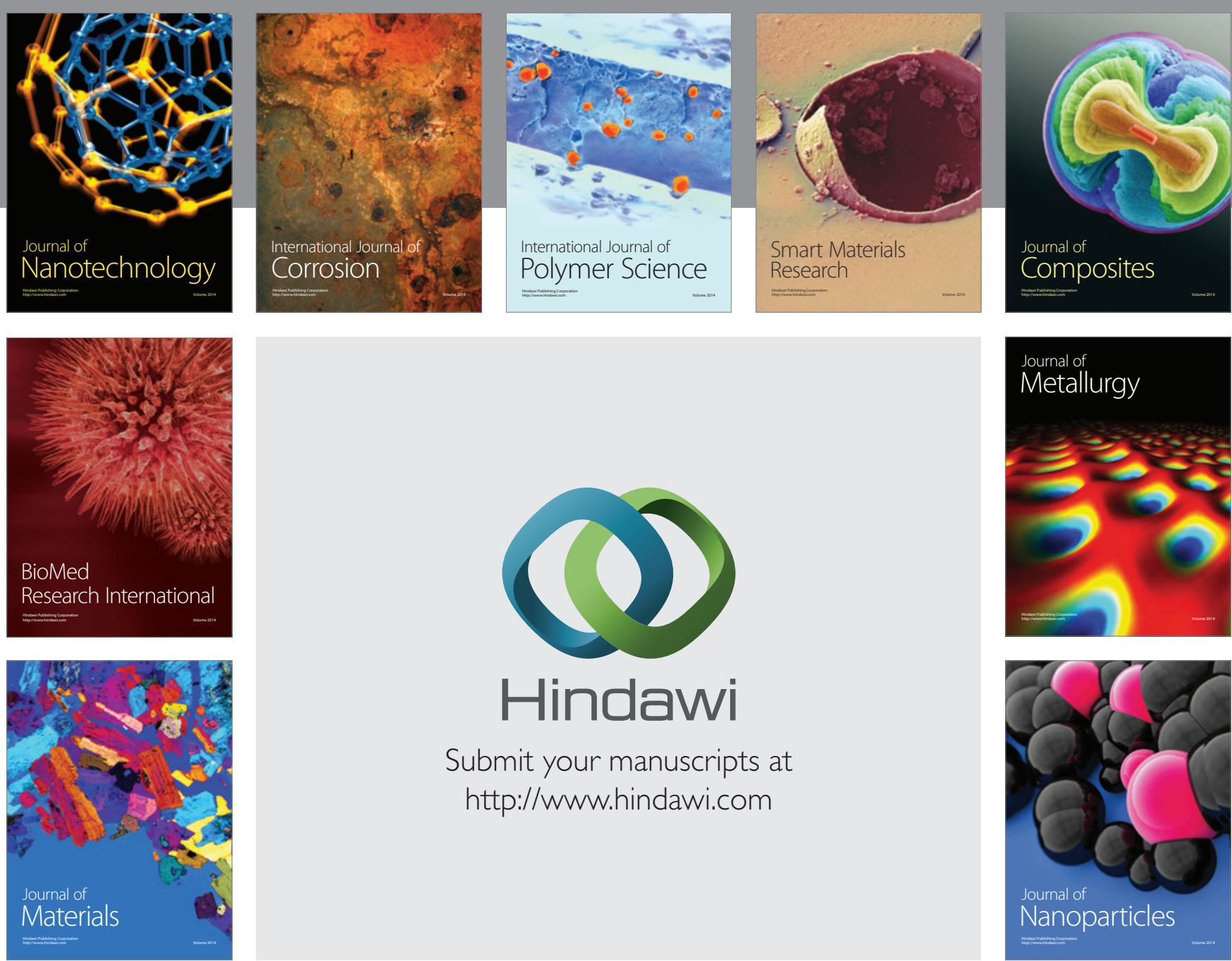

\section{Hindawi}

Submit your manuscripts at

http://www.hindawi.com

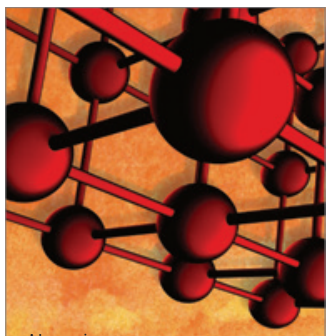

Materials Science and Engineering
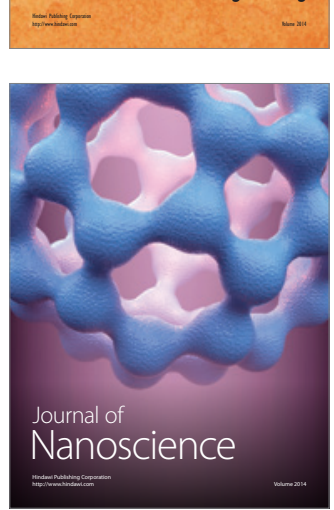
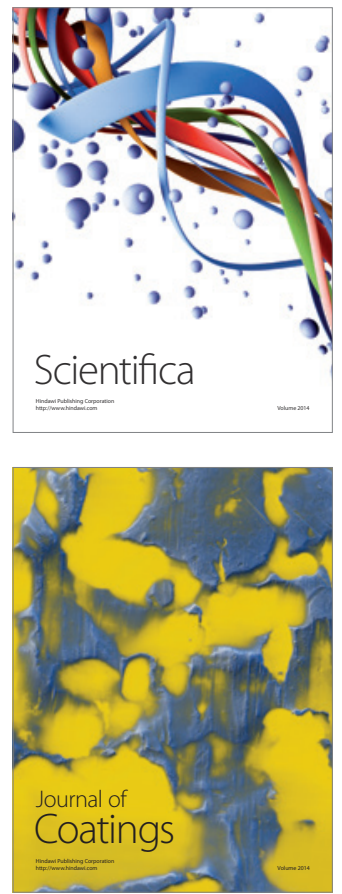
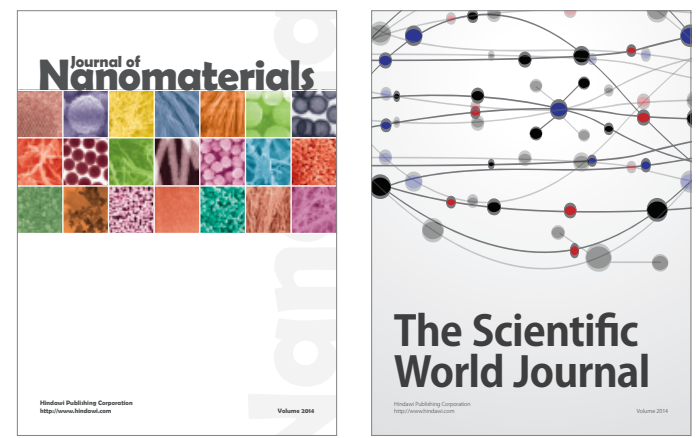

The Scientific World Journal
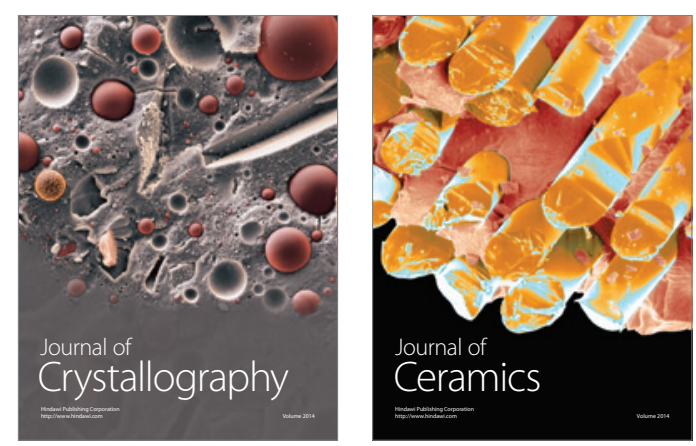
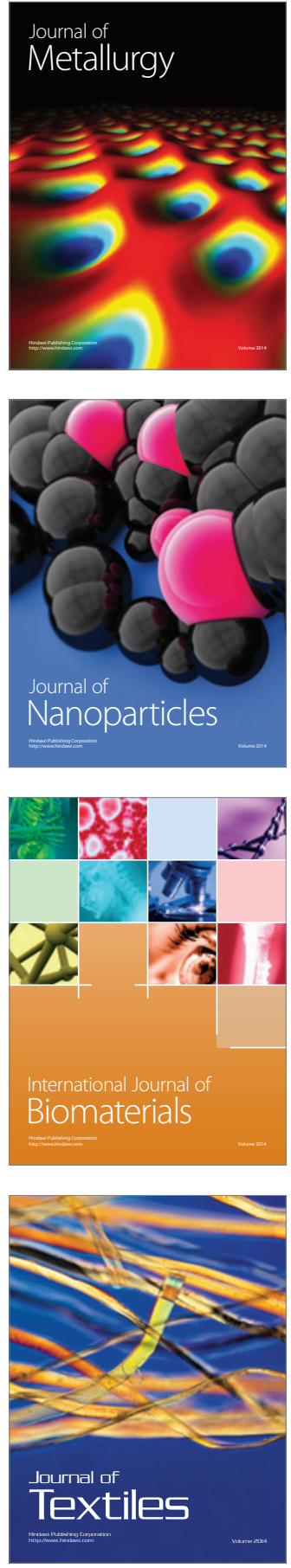